\title{
Could a crop model be useful for improving sunflower crop management?
}

\author{
Francis FLÉNET ${ }^{1}$ \\ Philippe DEBAEKE ${ }^{2}$ \\ Pierre CASADEBAIG ${ }^{2}$ \\ ${ }^{1}$ CETIOM, Avenue Lucien Brétignières, \\ 78850 Thiverval-Grignon, France \\ <flenet@cetiom.fr> \\ 2 INRA, UMR 1248 AGIR, \\ BP 52627, \\ 31326 Castanet-Tolosan cedex, \\ France \\ <debaeke@toulouse.inra.fr> \\ <casadeba@toulouse.inra.fr>
}

In France, there has been a stagnation in sunflower seed yield during the past 20 years. The annual mean seed yield has ranged from 2.1 to $2.7 \mathrm{t} \mathrm{ha}^{-1}$. The highest value was observed in 2007 , but it was mainly the result of the high rainfall during summer. During that period of time, the area cultivated in sunflower has decreased by almost $50 \%$. Overall, there has been a decrease in seed production, although there is a need for greater quantities because of the increased demand for biodiesel. Hence, both increases in seed yield and in the area cultivated in sunflower are necessary. Improvements in crop management would probably contribute to these objectives. However, during the past few years, sustainable agriculture has become a priority in the European Union. In France, the French government decided in 2007 that the applications of pesticides should decrease by $50 \%$ within 10 years. This has to be taken into account when improving crop management. The objective of this article is to review the main characteristics of sunflower crop management in France and in other countries, in order to emphasize the need for improvement and to evaluate if the recent advances in crop modelling could help to find solutions.

\section{Discussion}

\section{The main problems in sunflower crop management}

Sunflower crop management in France is characterized by few applications of pesticides. Most of the time, insects are not a major problem. Hence, only $40 \%$ of the sunflower area received one insecticide in 2006. The reduction of plant

\begin{abstract}
In France, there is a need for improved sunflower crop management, in order to meet the greater requirement for oil by increasing both seed yields and the area of this crop. The objective of this article is to review the main characteristics of sunflower crop management in France and in other countries, in order to emphasize the need for improvement, and to evaluate if the recent advances in crop modelling could help to find solutions. In France, a better adaptation of crop management to water availability is needed, as well as a more efficient control of diseases without applying more fungicides. The results of these objectives would also trigger major improvements in other countries, but there is also a need to control insects and to adapt crop management to the goals of oil quality. The main sunflower crop models are reviewed in this article, with an emphasis on the most recent ones. Their ability to contribute to improving sunflower crop management, although they do not take into account diseases and insects, is discussed. Confidence in the decisions based on simulations, and the way to evaluate it, is also examined.
\end{abstract}

Key words: sunflower, crop management, crop models, management strategies, model evaluation

population due to damage by slugs, birds or game animals has been observed more often. However, only $54 \%$ of the sunflower area was sprayed against slugs in 2006, while no treatments are allowed against birds or game animals. Moreover, the application of fungicides is rare (only $7 \%$ in 2006). Fungal diseases are mainly controlled by seed treatments, long crop rotation, destruction of volunteers and of some weeds, and by the use of resistant or tolerant varieties. However, pathological premature ripening due to phoma or macrophomina is often observed, especially in dry areas. Herbicides are applied in almost $100 \%$ of the area, but between-row cultivation also contributes to weed management. This cultural operation was observed in $41 \%$ of the area in 2006 . Hence, sunflower may contribute to the decrease in the application of pesticides in France, through an increase in the area of this crop to the detriment of other crops. This would be effective as long as improvements in crop protection were focused on other ways than increasing the application of pesticides. For instance, date of sowing, seeding rate and the amount of $\mathrm{N}$ fertiliser have an effect on several diseases, such as Phoma black stem $[1,2]$. This indicates that there are possibilities for decreasing disease incidence without applying fungicides.

In France, sunflower is mainly cultivated on clay soils. Most of the time, seeds are sown after a deep tillage (72\% of the area in 2006), while there is very little direct sowing (2\% in 2006). There is almost no irrigation (only $4 \%$ of the area in 2006). The range of soil depth is wide, resulting in a large range of seed yields. For instance, in south-west of France in 2006, mean yields were $2.28,2.34$ and $2.73 \mathrm{t} \mathrm{ha}^{-1}$, respectively, on shallow (13\% of the area), medium (75\%) and deep soils (12\%). However, there is little adaptation of crop management to the expected water availability (soil field capacity, expected rainfall and irrigation). The main adaptation to reduce the effect of water shortage is earlier sowing in south of France, because severe deficits in summer are expected. In the Aude region however, where mid-summer storms are predictable, the date of sowing is delayed. The objective is to postpone the seed filling period, so that it occurs during mid-summer. The amount of $\mathrm{N}$ fertiliser applied is also adapted to the target yield, which results from the expected water availability. However, there are no further adaptations of the crop management to the expected water availability. For instance, the droughttolerance of commercial cultivars, if it exists, is unknown and thus not available for farmer's decision.

The first objective of any improvement in crop management is a better adaptation to the expected water availability. It would result in more accurate date of sowing, planting density, amount of $\mathrm{N}$ fertiliser (more accurate target yield) and variety maturity type. The choice of the variety should also account for the differences in leaf area and in stomatal closure, which play an important role in drought tolerance [3]. The second objective is to control diseases more efficiently without foliar-applied fungicides, especially those responsible for premature ripening in dry areas.

In other countries, there are some differences in crop management, compared to France. The 
following section is not an exhaustive list of the main differences which have been noticed, but it is the description of three of them which could also be improved by crop modelling. Firstly, in countries other than France, crop management is sometimes more adapted to the expected water availability, especially through the target plant population. The objective of plant number per hectare in Australia is 20-25,000 in marginal dryland, 25-35,000 in favourable dryland, 35-50,000 in limited irrigation and 50-75,000 in full irrigation [4]. In the USA High Plains, plant population for irrigated sunflower should be between 42,000 and 54,000 final plant per hectare, while it should be lower for lower yield potentials [5].

Secondly, the occurrence of insect problems is more acute outside Western Europe, where insect damage on sunflower is less. In North America, there is a wide pest complex because sunflower is native to this region of the world [6]. On other continents, numerous insects also attack sunflower. For example, in Africa, sunflower has been grown for a long time as an ornamental plant. Insects attacking ornamental crops later moved to commercial ones [6]. In the countries where insects cause significant yield reductions, the planting date can play a role in controlling them. For instance, in Canada, delaying planting until late May or early June has been effective in reducing densities of stem weevil larvae [7]. It also helps to prevent the first major emergence of the overwintering sunflower midge population. On the contrary, early planting reduces seed damage of sunflower seed weevils because early planted sunflowers complete anthesis and are no longer susceptible to egg laying at the time of peak populations [7].

Thirdly, in some countries, crop management contributes to seed quality. In France, sunflower oil is mainly used for biodiesel or for food. Oil with a high oleic content is required for biodiesel. The quality required is obtained through the cultivation of high oleic varieties, while the rest of the crop management is similar to that for other varieties. However, planting date can affect the oil quality, because warm temperatures during anthesis and the seedfilling period increase the seed content in oleic acid [8]. Hence, in Australia, for example, planting dates are grouped into an early and a late sowing window [4]. For spring sowing, high oleic acid varieties are preferred. Hence, the high temperatures occurring during seed filling for this sowing time is not a problem. In order to produce high linoleic varieties, sowing in the late plant window (December-January) is recommended so that crops fill seeds in the cooler autumn months.
In order to adapt crop management accurately to each situation, many data are needed because environmental conditions are highly variable, between years and between locations. Hence, the optimum of one cultural operation is also highly variable from one experiment to another. For instance, Robinson [9] stated that "disagreement on the optimum plant population is common". Moreover, there are many cultural operations which interact with each other. For example, the optimum plant population density tends to be greater with irrigation $[8,10]$. It is not possible to conduct the huge number of factorial experiments needed for an accurate adaptation of crop management. In France, the recommendation of an early sowing date is mainly based on field surveys. For instance, in the south west of France, the results of 300 fields per year from 1996 to 2006 show a decrease in yield when the sowing date was delayed after 10 April [11]. The difference in yield was $0.27 \mathrm{tha}^{-1}$, between sowings before 10 April and after 10 May. However, these results are rough estimates, because they compare different fields with possible differences in other cultural operations and in soils. In order to take into account possible interactions with other factors (variety, soil depth...), and/or to give more site-specific recommendations, many more data would be necessary. There is also a need to keep adapting crop management to keep up with technical progress (new varieties...), and with changes in objectives (quality) and in environmental conditions (the possibility to irrigate or climate change). The number of years necessary to give recommendations taking into account these changes would be too great, if results from either experiments or surveys were used. All these difficulties can be overcome by using crop models, because thousands of situations can be simulated in a few hours, once these tools are validated.

\section{Sunflower crop models}

Villalobos [12] reviewed sunflower crop models at the $15^{\text {th }}$ International Sunflower Conference in Toulouse. At that time, several specific models of sunflower had been developed, and a few others were applicable to several crops including sunflower (generic models). These models are mathematical representations of crops and soils which take into account dynamically and on a daily basis the effects of weather and crop management on seed yield. The QSUN model was developed in the early nineties [13]. It takes into account sowing date, irrigation and variety. The OILCROP-SUN model [14] also considers these factors, along with fertiliser management.

Two models which have been developed since 2000 provide further possibilities. A simple model based on published relationships calculates oil quality along with seed yield [15]. The cultural operations taken into account are the effect of sowing date, plant density and variety. Another sunflower crop model was developed by Casadebaig [3] to gain new insight into the way to discriminate yield build-up between varieties. Generally, in sunflower models, varieties only differ in yield components and maturity types. In this new model, varietal parameters are required for crop development, leaf area and its ability to intercept light, response of leaf expansion and stomatal closure to soil water deficit, harvest index and the maximum percentage of kernel in achenes. These parameters are easily measurable, in order to be able to account for the dozens of new varieties appearing each year on the market [16]. Sowing date, plant density, irrigation and $\mathrm{N}$ fertiliser are also considered.

However, the sunflower crop models presented above do not include diseases, insects or weeds. There has been one attempt to connect the EPIC crop model adapted to sunflower to Phomopsis stem canker [17]. The climatic risk of contamination by ascospores was predicted from spring and summer rainfall. Then, the disease symptoms were simulated using the relationship between infected stems and the fraction of intercepted photosynthetically active radiation (IPAR), which was simulated by the EPIC crop model. Yield loss was then correlated with the symptoms, bearing in mind the period of contamination. The relationship between symptoms of Phomopsis stem canker and the IPAR or Leaf area index (LAI) was also reported by Debaeke and Estragnat [18]. Debaeke and Pérès [1] were also able to correlate Phoma black stem damage with IPAR or LAI at anthesis.

\section{The use of sunflower crop models to adapt crop management}

Sunflower crop models could be used to optimize crop management, by considering crop response to long-term historical weather records. For example, simulated seed yields were compared for a range of sowing dates, in order to select the best one [3, 19-21].

In Casadebaig [3], seed yield was simulated for 5 sowing dates, 7 locations, 3 available soil water content and 25 years (figure 1). Sowing dates were 1 March (D1), 25 March (D2), 15 April (D3), 10 May (D4) or 25 May (D5). Locations were representative of South of France, from the Western side (left on the figure 1) to the eastern (right on the figure 1): Agen (ACE), Auch (AUC), Blagnac (BLA), Villefranche de Lauragais (VFL), Castelnaudary (CAS), Carcassonne (CAR) and Montpellier (MON). Soil water capacities were $80 \mathrm{~mm}(\mathrm{~S} 1), 150 \mathrm{~mm}$ (S2) or $250 \mathrm{~mm}$ (S3). In most combinations of 


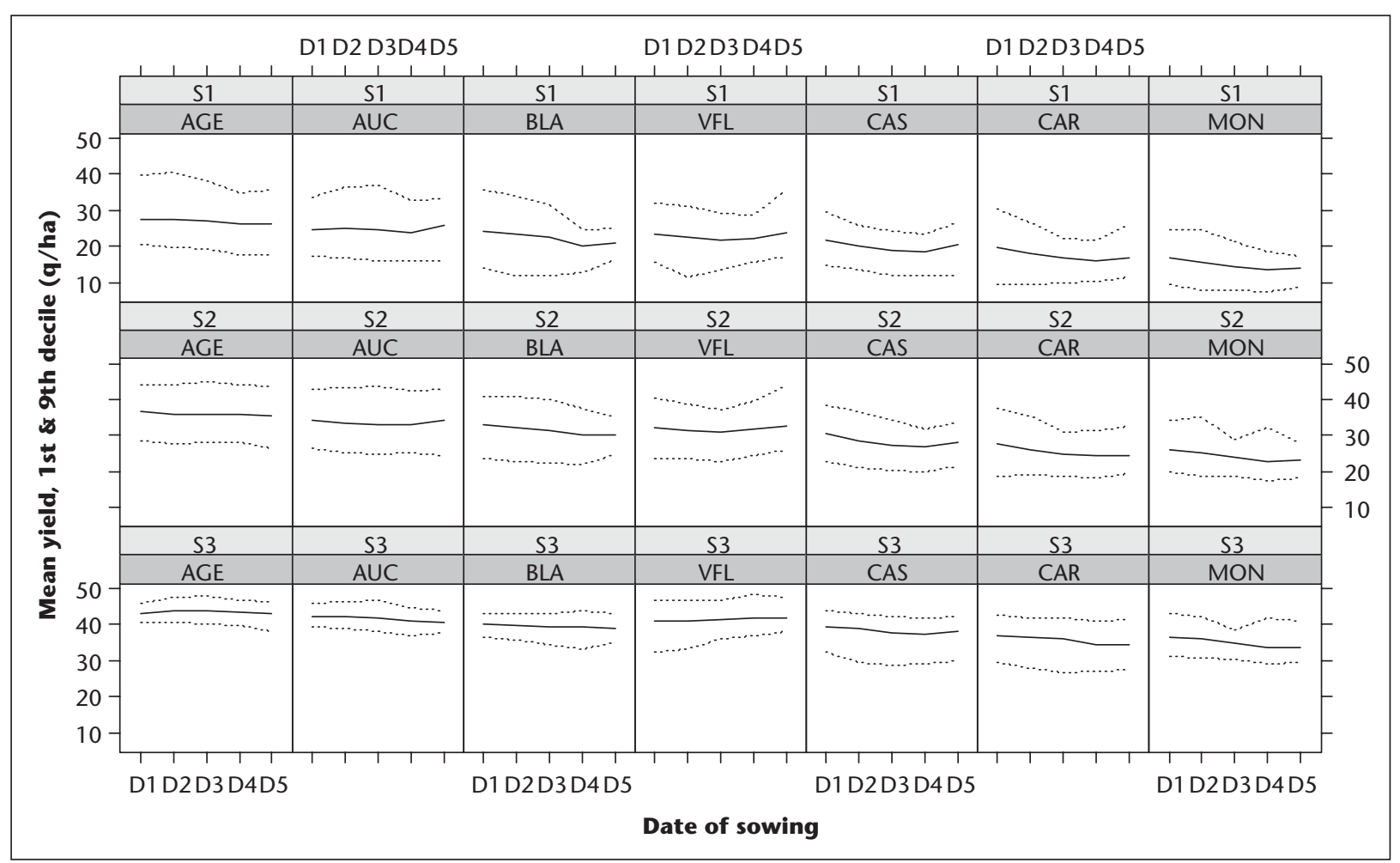

Figure 1. Simulated seed yield versus sowing date in 7 locations and for 3 soils [3].

location $\times$ soil water capacity, seed yield decreased with delaying the sowing date until the third or the fourth date, because of a greater water deficit. Then, an increase in seed yield was observed between the third or fourth date and the fifth date, due to the delaying of seed filling until the period of mid-summer storms. This pattern was less marked on deep soils with high water capacities. Hence, depending on location and on soil water capacity, the greatest yield could be obtained at the early sowing date, at both the early and the late sowing dates because of mid-summer storms, or at all sowing dates because of a little water deficit due to both deep soils and humid climates.

The best maturity type was similarly studied by Meinke et al. [19]. Debaeke et al. [22] and Rinaldi et al. [20] also compared the effect of irrigation strategies on simulated yields. Oil seed quality can also be taken into account, along with seed yield, when using a crop model to optimize crop management [15].

These simulations could assist farmers in making management decisions. It provides information on the effect of one or several cultural operations, in each specific soil $x$ climate situation, which takes into account the variability between years. Experiments or surveys fail to give such precise information. However, users of crop models should be aware of 2 limits: (1) accuracy and robustness, and (2) relevance (factors not taken into account). Crop models will be powerful tools to assist farmers as long as these limits are properly managed.

Model accuracy is the ability to give simulations close to the measurements. Robustness is the capability to be accurate in other environmental conditions than those prevailing for the data set used for calibration. Both are crucial for helping farmers to make good decisions. Model accuracy is evaluated by comparing simulations and measurements not used for calibration. However, the minimum of accuracy necessary to help farmers to make the best decision is usually not discussed. This would need specific works that have never been done when using sunflower crop models. For instance, Rinaldi et al. [20] observed a good correlation between simulated yields and independent measurements (almost perfect regression slope (0.95) and intercept (-0.07), and a fairly good $R^{2}$ value of 0.74 ). Observed values were obtained for several years, in locations, irrigation regimes and sowing dates similar to those prevailing for the use of the model. This evaluation of the model was encouraging. However, it was not a proof that simulations were accurate enough to make the good decision, which was to use a threshold value of $40 \%$ of total soil water to trigger irrigation. Moreover, robustness is not usually discussed, even though the ability to give results in other situ- ations than those prevailing in experiments is exactly the expected benefit of a crop model. Many factors affecting seed yield or quality are not taken into account by crop models. For example, sowing date does not only have an effect on climate conditions during crop growth. Diseases and insects are also affected $[7,23,24]$. Models considering these factors would be very helpful. However, this does not seem as if it will become a reality in the near future. There are numerous diseases and insects which depend on many other factors than those in the sunflower field (cropping history, spatial cropping pattern...). Moreover, their effects depend on plant tolerance or resistance, and on the application of pesticides.

However, crop models could be useful for contributing to define management strategies. Debaeke and Nolot [9] illustrated the definition of management strategies based on a target yield (which depended on water availability), and also based on the combination of avoidance and/or tolerance of limiting factors and vegetative rationing. The limiting factors involved were both nutritional and disease ones. For each combination of soil and climate, a crop model would be useful for establishing the potential yields allowed by the water availability, solar radiation and temperature. Results of potential yields would depend on sowing date, plant number and on variety. These results could be associated with the knowledge 
of diseases and insects in order to define management strategies. One strategy could aim at the maximum yield. According to the hypothesis that several combinations of sowing date $x$ plant number $x$ variety exist, the one recommended would be that minimizing the risks of major diseases and insects. In order to minimize them further, other management strategies could aim at lower target yields. Crop models could also help to estimate the risks of diseases and insects by simulating variables correlated with them. Examples of such correlations are given in section 2 of this article (IPAR or LAl correlated with Phoma black stem or Phomopsis stem canker). Models could also be used for insect damage. For instance, they could simulate the stages of development when sunflower is more susceptible to damage from a particular insect.

\section{Conclusion}

The issue investigated in this article is the possibility of using crop models for improving sunflower crop management. In France, a better adaptation of crop management to water availability is needed, as well as a more efficient control of diseases without applying more fungicides. A huge number of experiments would be needed to reach these objectives, while surveys give only rough estimates on the effect of cultural operations. Moreover, both experiments and surveys need too many years to keep up with the continuous technical progress (new varieties...), and for the quick changes in objectives (quality) and in environmental conditions (the possibility to irrigate or climate change) that are expected in the future. Crop modelling is the only way to obtain data quickly enough. Similarly, crop models could be helpful in countries other than France, although their needs for improving crop management may be different. There have been recent advances in sunflower crop models, in simulating oil quality and in defining differences between varieties. Although diseases and insects are still not taken into account, crop models could be used to trigger management strategies. These strategies would be based on simulated potential yields and on knowledge of diseases and insects. However, the condition for using simulated results to improve crop management is the confidence in the model. Until now, models have been mainly evaluated by comparing the simulations and the measurements made in a few independent experiments, which is not enough. There is a need to evaluate the ability of models to help to make the best decision in a large range of environmental conditions.
Acknowledgements. The authors wish to thank the organizers of the $17^{\text {th }}$ International Sunflower Conference for their invitation to write this article.

\section{REFERENCES}

1. DEBAEKE P, PÉRÈS A. Influence of sunflower (Helianthus annuus L.) crop management on Phoma black stem (Phoma macdonaldii Boerema). Crop Prot 2003; 22: 741-52.

2. SEASSAU C, MESTRIES E, DEBAEKE $P$, DECHAMP-GUILLAUME G. Effects of nitrogen and water on premature ripening caused by Phoma macdonaldii, a fungal pathogen of sunflower. In: Proc. 17th Int. Sunfl. Conf., Cordoba Spain. Int. Sunfl. Assoc., Paris, France. 2008.

3. CASADEBAIG P. Analyse et modélisation dynamique de l'interaction génotype-environnement-conduite de culture: application au tournesol (Helianthus annus L). PhD Thesis, INP Toulouse, 2008, $134 \mathrm{p}$.

4. SERAFIN L, BELFIELD S, MCCAFFERY D. SUNFLOWER. In: Farrell T, Serafin L, Kneipp J, eds. Summer crop production guide. Australia: New South Wales Department of Primary Industries, 2007.

5. MEYER R, BALTENSPERGER DD, SCHLEGEL A] KRALL JM, LEE C, SHROYER JP. Gronomic practices. In: Meyer R, Belshe D, O'Brien D, Darling R, eds. High Plains Sunflower Production Handbook. Kansas State University Agricultural Experiment Station and Cooperative Extension Service, USA, 1999: p. 1-3.

6. CHARLET LD, BREWER G], FRANZMANN B. Insect pests. In: Schneiter AA, ed. Sunflower Technology and Production. Agronomy Monograph 35. Madison, WI, USA: ASA, CSSA and SSSA, 1997.

7. MANITOBA AGRICULTURE. The sunflower production guide. Winnipeg, Manitoba: MAFRI Publications, 2006; (40 p).

8. BLAMEY FPC, ZOLLINGER RK, SCHNEITER AA. Sunflower production and culture. In: Schneiter AA, ed. Sunflower Technology and Production.Agronomy Monograph 35. Madison, WI, USA: ASA, CSSA and SSSA, 1997.

9. ROBINSON RG. Production and culture. In: Carter JF, ed. Sunflower science and technology. Agronomy Monograph 19. Madison, WI, USA: ASA, CSSA and SSSA, 1978.

10. DEBAEKE $P$, NOLOT JM. Testing crop management systems for sunflower in South-West France. In: Proc. 15th Int. Sunfl. Conf., Toulouse, France. Paris, France: Int. Sunfl. Assoc, 2000.

11. CETIOM. IN: CETIOM, ED. Tournesol Régions sud 2008. Brochures CETIOM. 2008; (26 p).
12. VILLALOBOS FJ. Principles and applications of sunflower crop simulation models. Plenary session C - Agronomy and Environment. In: Proc. 15th Int. Sunfl. Conf., Toulouse, France. Paris, France: Int. Sunfl. Assoc, 2000.

13. CHAPMAN SC, HAMMER GL, MEINKE H. A sunflower simulation model. I Model development. Agron / 1993; 85: 725-35.

14. VILLALOBOS FJ, HALL AJ, RITCHIE JT, ORGAZ F. Oilcrop-Sun: A development, growth, and yield model of the sunflower crop. Agron / 1996; 88: 403-16.

15. PEREYRA-IRUJO GA, AGUIRREZABAL LAN. Sunflower yield and oil quality interactions and variability: Analysis through a simple simulation model. Agric For Meteor 2007; 143: 252-65.

16. CASADEBAIG $P$, DEBAEKE $P$, LECOEUR I. Thresholds for leaf expansion and transpiration response to soil water deficit in a range of sunflower genotypes. Eur / Agron 2008; (in press).

17. DEBAEKE P, CHABANIS I. An integrated simulation model of yield loss by a fungal pathogen: stem canker (Phomosis helianthi) in sunflower. In: Proc. 1st Int. ESA Symp. on Modelling Cropping Systems, Lleida, Spain. 1999.

18. DEBAEKE P, ESTRAGNAT A. A simple model to interpret the effects of sunflower crop management on the occurrence and severity of a major fungal disease: Phomopsis stem canker. Field Crops Res 2003; 83: 139-55.

19. MEINKE H, HAMMER GL, CHAPMAN SC. A sunflower simulation model. II. Simulating production risks in a variable sub-tropical environment. Agron / 1993; 85: 735-42.

20. RINALDI M, LOSAVIO N, FLAGELLA Z. Evaluation and application of the OILCROP-SUN model for sunflower in southern Italy. Agric Syst 2003; 78: 17-30.

21. SORIANO MA, ORGAZ F, VILLALOBOS FJ, FERERES E. Efficiency of water use of early plantings of sunflower. Eur J Agron 2004; 21: 465-76.

22. DEBAEKE $P$, CABELGUENNE M, HILAIRE $A$, RAFAILLAC D. Crop management systems for rainfed and irrigated sunflower (Helianthus annuus L.) in south-western France. J Agric Sci Camb 1998; 131: 171-85.

23. LETERME P. Phomopsis et Sclerotinia Feuilles/ bouton: des essais non spécifiques. Oléoscope 1992; 10: 8-10.

24. DEBAEKE P, MOINARD J, DELOS M. Simulating the influence of sowing date on disease occurrence in sunflower. In: Proc. 2nd Int. ESA Symp. on Modelling Cropping Systems, Florence, Italy. 2001. 